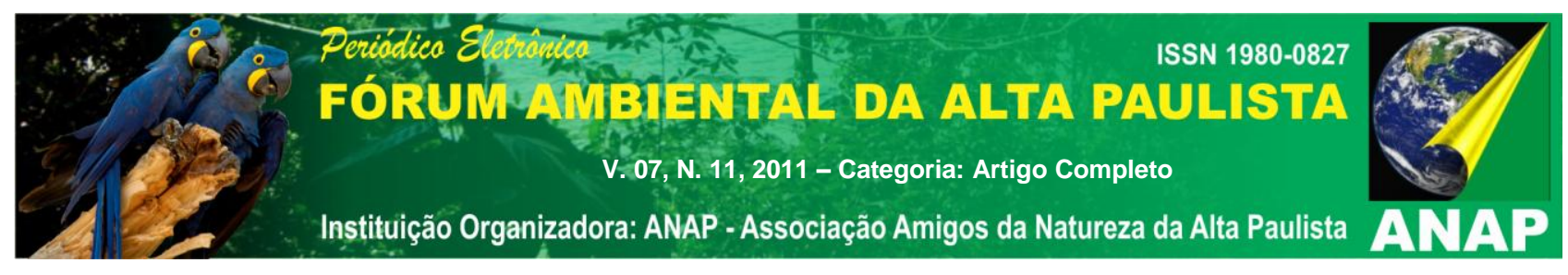

\title{
PERSPECTIVAS PARA A QUALIFICAÇÃO PROFISSIONAL NO SETOR SUCROALCOOLEIRO
}

\author{
Higuchi Cristiane Aparecida Pelegrin ${ }^{1}$ \\ Osmar de Carvalho Bueno ${ }^{2}$
}

\begin{abstract}
RESUMO: A cultura da cana de açúcar é de relevante importância social e econômica no Estado de São Paulo devido, principalmente à produção de açúcar e biocombustível, movimentando um representativo volume monetário, bem como relevante quantidade de empregos temporários gerados no período de colheita. Analisando a situação, do corte manual versos o corte mecanizado verificamos que ainda é uma atividade frequentemente associada à poluição ambiental pela queima prévia da palha. Neste contexto a mecanização necessariamente deve se dar ao mesmo tempo que a criação de novos postos de trabalho, ou seja, a adoção de novas tecnologias e o estabelecimento de políticas públicas garantidoras do nível de empregos e renda perdidos. Percebe-se necessidade de intervenção governamental no sentido de elaboração de políticas publicas desenvolvidas com apelo regional, a fim de assegurarem meios de sobrevivência. O sistema da cana-de-açúcar é complexo e o objetivo deste trabalho é discutir a recolocação dos cortadores de cana em atividades que the proporcionem renda, dignidade e melhor qualidade de vida. Portanto as políticas publicas devem ser planejadas priorizando o desenvolvimento regional tanto na região de destino, quanto nas regiões de origem dos trabalhadores, de forma a diminuir a necessidade de migração, fixando o homem em suas oportunidades assegurando meios de sobrevivência. A iniciativa governamental de qualificação através do PlanSeQ Plano Setorial de Qualificação é muito interessante porém se comparada à necessidade do setor ainda representa pouco pela necessidade da mecanização.
\end{abstract}

Palavras- Chave:, Cana de Açúcar. Mão de Obra. Políticas Públicas.

\section{INTRODUÇÃO}

\footnotetext{
1 Bacharel em Ciências Contábeis, Faculdade de Ciências Agronômicas - UNESP. Doutoranda em Agronomia/Energia na Agricultura. higuchi@fca.unesp.br

${ }^{2}$ Engenheiro Agrônomo, Faculdade de Ciências Agronômicas - UNESP. Professor Adjunto. osmar@fca.unesp.br
} 


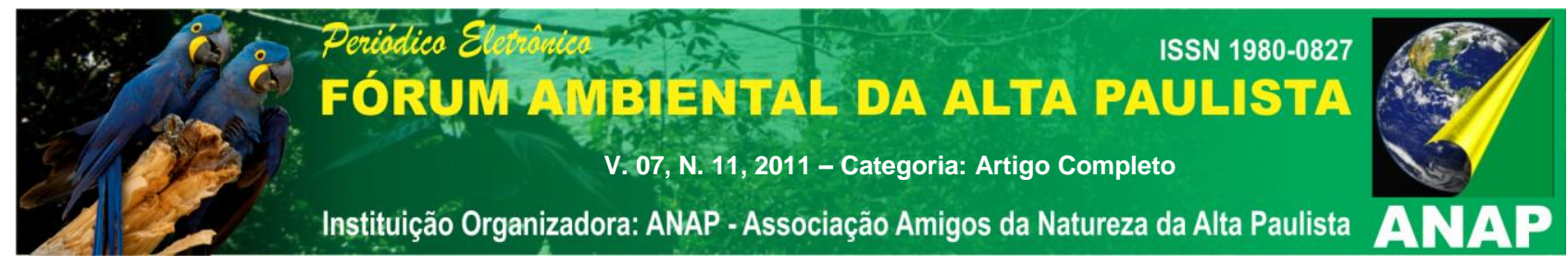

Conforme relatório anual da Companhia Nacional de Abastecimento (Conab) de 2011, a lavoura da cana de açúcar continua em expansão no Brasil. Os maiores índices de aumento de área cultivada ocorrem em São Paulo, Mato Grosso do Sul, Goiás e Minas Gerais. Nestes Estados, além do aumento da área cultivada, outras novas usinas entraram em funcionamento na safra passada. Porém na safra de 2010/11, a cana de açúcar apresentou um desenvolvimento aquém do que aconteceu na safra anterior em decorrência de um clima adverso com chuvas escassas em toda região CentroOeste e Sudeste (CONAB 2011).

Segundo o PlanSeQ Plano Setorial de Qualificação Sucroalcooleiro Nacional 2010, o setor vem a cada dia aprendendo a utilizar todas as qualidades desta rica matéria prima que é a cana de açúcar. Com a produção de açúcar, etanol e bioenergia. A energia elétrica produzida a partir do bagaço de cana já representa mais de $4,5 \%$ da matriz de energia elétrica brasileira.

O objetivo deste trabalho é estudar o quadro de incerteza sobre o que ocorrerá do ponto de vista dos cortadores de cana de açúcar, quais os efeitos sobre o emprego decorrentes da necessidade de mecanização do corte em cumprimento a legislação e a política pública governamental de requalificação para os empregados que serão dispensados em virtude da mecanização.

A metodologia utilizada no presente trabalho constituiu em levantamento bibliográfico de autores recentes que estudam sobre consequências do corte manual e mecanizado da cana de açúcar sob a ótica ambiental, social, legal e econômica. Além de uma análise crítica do PlanSeQ Sucroalcooleiro, Plano Setorial de Qualificação para o setor, no processo de eliminação de postos de trabalho em substituição à mecanização da colheita.

Levantamento realizado pela USP de Ribeirão Preto, comentado no PlanSeQ Sucroalcooleiro, mostra que o PIB do setor atingiu US $\$ 28,1$ bilhões em 2008, cerca de $2 \%$ do PIB brasileiro, gerando uma arrecadação de impostos (IPI, ICMS, PIS, e COFINS) da ordem de US $\$ 9,86$ 


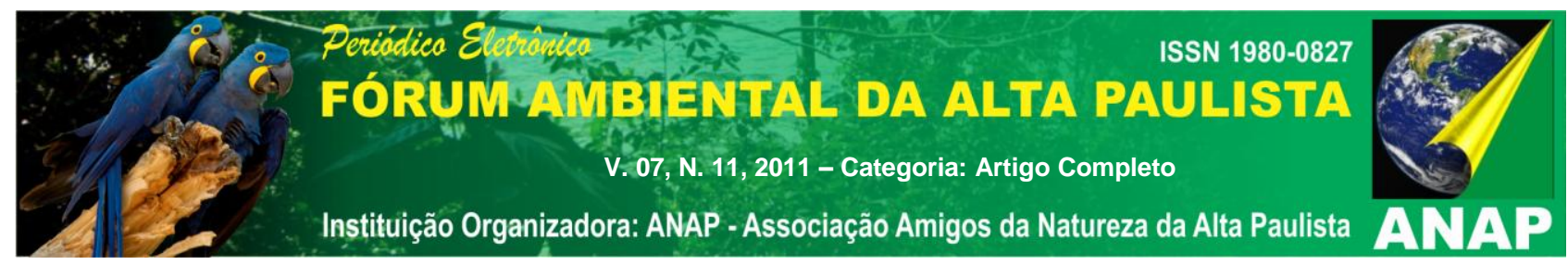

bilhões. O setor ainda movimenta uma imensa cadeia de insumos e serviços agrícolas e industriais.

O corte é precedido da queima da palha da planta, o que torna o trabalho mais seguro e rentável ao trabalhador. Nas operações de colheita envolvendo a queima prévia do canavial, ocorrem muitos danos ao meio ambiente e à população, sendo esse o principal motivo da promulgação da Lei n. 11.241 de 19/09/02, que restringe a queima como prática auxiliar na operação de colheita (BUZOLIM, 1997; NERY, 2000).

A questão também passa pelos excessos de trabalho impostos aos cortadores de cana, portanto sugere-se a modificação do sistema de produção, substituindo o trabalho manual por máquinas. Essa possibilidade, embora desejável, esbarra na criação de postos de trabalho que compensem esta perda (ALVES 2006).

Para os usineiros a mecanização da colheita além de envolver novos custos, ainda não está tecnicamente resolvida. Existem problemas, tais como: a reduzida longevidade do canavial, quando submetido ao corte mecânico, a ocorrência de novas pragas e o não aproveitamento da palha para a geração de energia elétrica (ALVES 2009).

Neste contexto o governo do estado de São Paulo negociou acordo com o setor sucroalcooleiro em relação aos prazos de utilização de queimadas nos canaviais do referido estado. $O$ acordo prevê a antecipação dos prazos para as áreas mecanizáveis e não mecanizáveis. Essas - áreas não mecanizáveis - que possuíam o prazo inicial programado para 2031, tiveram antecipação para 2017; aquelas - áreas mecanizáveis - que tinham seu prazo delimitado para 2021, tiveram antecipação para 2014. Obteve inclusive adesão da União das Indústrias de Cana de Açúcar, ÚNICA, a qual possui grande representatividade no setor (ANSELMI, 2007).

Segundo FAPESP (2011) o balanço da safra da cana de açúcar no estado de São Paulo no período de 2010 a 2011, aponta que as usinas e fornecedores estão cumprindo as metas do Protocolo Agroambiental do Setor Sucroalcooleiro em acabar com a queima da palha da cana no estado entre 


\section{Periódica

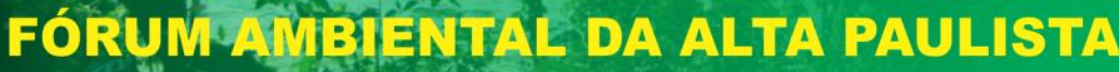 \\ V. 07, N. 11, 2011 - Gategoria: Artigo Completo \\ Instituição Organizadora: ANAP - Associação Amigos da Natureza da Alta Paulista}

2014 e 2017. Ainda de acordo com a FAPESP (2011) no balanço da safra $2010 / 2011$, as usinas mecanizaram $70,3 \%$ e os fornecedores $21,1 \%$ das suas áreas colhidas, sendo estes últimos responsáveis por $30 \%$ da área cultivada no Estado. Isto significa que 14,2 milhões de toneladas de poluentes e 2,4 milhões de toneladas de $\mathrm{CO}_{2}$ que deixaram de ser emitidos.

Porém, segundo Moraes (2007), no Estado de São Paulo a velocidade da adoção da colheita mecanizada varia bastante entre as principais regiões produtoras do Estado. Em Ribeirão Preto estima-se que a mecanização tenha atingido $60 \%$ da colheita enquanto em Piracicaba esta proporção é bem menor, ao redor de $20 \%$. Este fato explica-se por alguns fatores:

1. A região de Ribeirão Preto é plana, favorecendo a mecanização com máquinas atualmente disponíveis, enquanto mais de $70 \%$ das terras de Piracicaba têm declividade superior a $30 \%$.

2. A estrutura fundiária entre ambas também é diferente em quanto na região de Ribeirão Preto existe grandes produtores, com escala que justifica a compra de uma máquina colhedora, Piracicaba a grande maioria é de pequenos produtores, que não são capitalizados para adquirirem colhedoras mecânicas, além de não terem escala de produção eficiente para a colheita mecânica.

A tendência de mecanização na região Sul é irreversível e tende a se acelerar por diversos motivos. As usinas estão investindo em co-geração de energia elétrica a partir da queima do bagaço da cana, para comercialização de energia neste mercado. Alem do bagaço a palha também pode ser utilizada como matéria prima na co-geração de energia elétrica, o que estimula a usina a deixarem de queimá-la. (MORAES 2007).

Ambientalmente a eliminação das queimadas é uma vitória para a população em geral, porém socialmente é uma medida que marginalizará em sua maioria os trabalhadores com pouca escolaridade. A saúde ambiental ao 
defender a eliminação da queima da cana de açúcar, defronta-se com a busca de alternativas de inclusão dos cortadores e suas famílias (RIBEIRO e FICARELLI, 2010).

Para Silva (2005), as condições de trabalho dos cortadores de cana são péssimas, tendo sua vida útil comparada á de um escravo na época do Brasil colônia, a autora aponta denúncias do ministério público e da imprensa sobre as más condições de trabalho e de vida desses cortadores, na maioria migrantes. Em muitos casos há uma exigência mínima de corte, podendo o cortador ser substituído por outro mais produtivo a qualquer momento.

È impossível negar a penosidade do trabalho do cortador de cana. É uma atividade que além de expor o trabalhador a toda sorte de intempérie, pois as temperaturas em época de safra podem chegar a $40^{\circ} \mathrm{C}$, risco de acidentes com animais peçonhentos, intoxicação por agrotóxicos entre outros, ainda é submetido a um ritmo acelerado de trabalho, na medida em que o ganho geralmente é por produção (ALESI e NAVARRO, 1997).

\section{DESENVOLVIMENTO}

Argumentos de que 2005, havia aproximadamente 520 mil empregados envolvidos diretamente na cultura da cana de açúcar no Brasil, e cuja escolaridade média era de 3,9 anos de estudo; $70 \%$ tinham até o quarto ano de estudo e destes 154 mil podem ser considerados analfabetos funcionais, ou seja, toda pessoa que sabe ler e escrever seu próprio nome, assim como efetua cálculos básicos, porém é incapaz de interpretar o que lê, impossibilitando seu desenvolvimento pessoal e profissional ( MORAES 2007).Tornam evidentes a necessidade de uma discussão sobre a qualificação e a capacitação para recolocação desses profissionais no mercado de trabalho.

De acordo com Baccarin (2010), a divisão de tarefas dentro da indústria sucroalcooleira e o respectivo número de pessoal ocupado no período 
junho de 2007-2009, junho é o mês em que a safra canavieira está em seu ápice no estado de São Paulo podendo ser observados na Tabela 1.

Tabela 1 : Pessoas Ocupadas em Empresas sucroalcooleiras, de acordo com o Tipo de Ocupação Estado de São Paulo, junho de 2007, 2008 e 2009.

\begin{tabular}{|c|c|c|c|}
\hline Mês & 2007 & 2008 & 2009 \\
\hline 1.Pessoas ocupadas na Agricultura & 246.616 & 242.423 & 220.209 \\
\hline 1.1 Trabalhadores Canavieiros não Qualificados & 212.966 & 205.495 & 182.735 \\
\hline 1.2 Trabalhadores da Mecanização Agrícola & 26.289 & 28.946 & 30.036 \\
\hline 1.3 Outras Pessoas Ocupadas na Agricultura & 7.361 & 7.982 & 7.438 \\
\hline 2. Pessoas Ocupadas na Indústria & 32.938 & 33.263 & 34.586 \\
\hline $\begin{array}{l}\text { 3. Pessoas Ocupadas em Atividades Administrativas } \\
\text { E de Apoio }\end{array}$ & 76.348 & 82.907 & 85.174 \\
\hline
\end{tabular}

Média do ano

$355.362 \quad 358.593 \quad 339.969$

Fonte:Adaptado MTE (2009) citado por Baccarin 2010.

Os dados de pessoal ocupado na indústria, em atividades administrativas e de apoio, registraram crescimento no período em análise. Observa-se também que diminuiu o número de Pessoas Ocupadas na Agricultura, dentre elas a queda se concentrou nos trabalhadores canavieiros não qualificados.

$\mathrm{Na}$ cultura da cana-de-açúcar o impacto do desemprego aparece mais, devido à quantidade de trabalhadores envolvidos na colheita. É uma mão de obra sem qualificação para maioria das outras atividades urbanas e agrícolas. Na Lei 11.241 em seu Artigo 10, requer a participação dos municípios, usinas, e sindicatos rurais para que em conjunto criem programas de requalificação para o elevado numero de trabalhadores (VIEIRA e PINHEIRO, 2004).

Segundo Moraes (2007), a mecanização da colheita altera o perfil do empregado: cria oportunidades para tratoristas, mecânicos, condutores de colhedoras, técnicos em eletrônica, dentre outros, e reduz, em 
maior proporção a demanda dos empregados de baixa escolaridade. Portanto para a inserção dos cortadores nesta nova fase da indústria canavieira se faz necessário à alfabetização, qualificação e treinamento desta mão de obra, para estar apta a atividades que exijam maior escolaridade neste ou em outro segmento.

Para Moraes (2007), no Estado de São Paulo, entre as safras de 2006/2007 e 2020/2021, conforme pode ser observado na Tabela 2, o número de empregados envolvidos na produção de cana-de-açúcar, açúcar e álcool passará de 260,4mil para 146,1 mil, ou seja, apontando uma redução de 114 mil empregos neste período.

Tabela 2: Estimativas da redução do número de empregados dos setores de cana de açúcar, açúcar e álcool no estado de São Paulo.

\begin{tabular}{lcccc}
\hline & $\mathbf{2 0 0 6 / 0 7}$ & $\mathbf{2 0 1 0 / 1 1}$ & $\mathbf{2 0 1 5 / 1 6}$ & $\mathbf{2 0 2 0 / 1 1}$ \\
\hline Produção de cana de açúcar (milhões t) & 299 & 370 & 457 & 544 \\
Área colheita mecânica & $40 \%$ & $70 \%$ & $100 \%$ & $100 \%$ \\
$\begin{array}{l}\text { Número de empregados (mil empregados) } \\
\text { colheita manual }\end{array}$ & 189,6 & 107,4 & 0 & 0 \\
colheita mecânica & 15,5 & 30,8 & 59,5 & 70,8 \\
& & & & \\
Indústria & 55,3 & 62,6 & 68,3 & 75,3 \\
Total mil empregados & $\mathbf{2 6 0 , 4}$ & $\mathbf{2 0 0 , 8}$ & $\mathbf{1 2 7 , 8}$ & $\mathbf{1 4 6 , 1}$ \\
\hline \hline
\end{tabular}

Fonte:Única 2007 citada em MORAES (2007)

Ainda Moraes (2007) observa que na indústria é esperado um aumento de 20 mil empregados, enquanto na lavoura canavieira o número passará de 205,1 mil empregados para 70,8 mil, ou seja, uma queda de 134,3 mil. A previsão é que não haja colheita manual na safra 2015/16, para áreas mecanizáveis e 2020/2021 para áreas não mecanizáveis

Para que parte dos empregados agrícolas sejam realocados para as atividades do corte mecanizado, é necessário capacitação e qualificação (MORAES, 2007). 


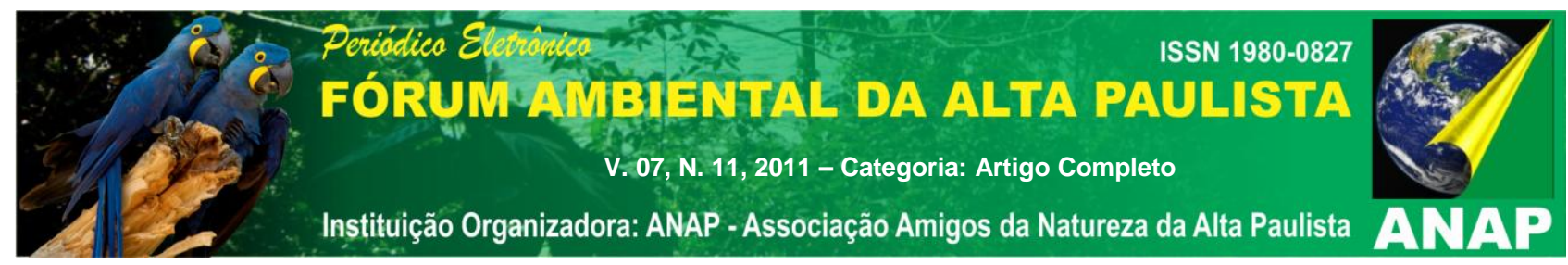

Ribeiro e Ficarelli (2010) verificam que na perspectiva da legislação do corte manual e de sua substituição pelas máquinas, somente metade dos cortadores entrevistados apresentaram planos alternativos de trabalho. Pouco deles planejam estudar, pois dizem não ter mais idade para isso ou porque abandonaram os estudos há muitos anos, falta de tempo livre para os estudos, falta de incentivos e de cursos profissionalizantes, e a inviabilidade econômica, não só para pagar um curso privado, mas para reduzir a jornada de trabalho para estudar.

Entretanto a outra metade dos entrevistados mostrou-se disposta a voltar a estudar para ter uma profissão ou até mesmo a ler e escrever. A falta de qualificação ainda é um problema não só para os adultos e idosos, mas também para os jovens (RIBEIRO e FICARELLI, 2010).

Cardoso et al (2010) ao discutirem a capacitação da mão de obra no setor sucroalcooleiro pesquisaram três usinas no estado de São Paulo, onde foi apontada a carência de pessoal capacitado em praticamente todas as funções agrícolas, com dificuldade para encontrar operadores de máquinas de grande porte (colhedoras, motoniveladoras) e mecânicos de manutenção colhedoras. Ainda comentam que as usinas com maior índice de mecanização (80\%), apresentam um quadro de funcionários com maior escolaridade, aproximadamente $52 \%$ igual ou superior ao ensino médio completo; já nas usinas com menor índice de mecanização (em torno de 40\%), predominou a contratação de trabalhadores com escolaridade igual ou inferior ao ensino fundamental completo.

Os trabalhadores entrevistados pelos autores consideravam a necessidade e importância da capacitação, contudo raramente tomavam iniciativas nessa direção, participando apenas de cursos direcionados especificamente para as funções que exerciam oferecidos pelas usinas. Contudo quando argüidos sobre os benefícios que a capacitação poderia proporcionar, a maioria dos entrevistados demonstrou preocupação com a 
perda do emprego e reconheceu que a capacitação poderia ser uma alternativa a essa situação indesejada CARDOSO et al. (2010)

$\mathrm{Na}$ necessidade urgente de capacitação para estes trabalhadores o Plano Nacional de Qualificação (PNQ) que é parte integrada do Sistema Nacional de Emprego (SINE), e pretende estabelecer uma articulação entre o Trabalho, a Educação e o Desenvolvimento, considerando que a qualificação social profissional um direito do trabalho e instrumento indispensável á sua inclusão e aumento de sua permanência no mundo do trabalho.

O Plano Nacional de Qualificação (PNQ) é implementado por meio de PlanteQs, Planos Territoriais de Qualificação, PlanSeQs, Planos Setoriais de Qualificação, ProEsQs, Projetos Especiais de Qualificação e Certificação Profissional.

Os PlanSeQs contemplam ações de qualificação social e profissional e serão propostos pelas entidades demandantes no caso do setor sucroalcooleiro através da UNICA, ou definidos pelo MTE.

O PlanSeQ Sucroalcooleiro de 2010 trata da qualificação profissional para o setor, e tem o objetivo de qualificar profissionalmente 12.600 trabalhadores (as) que será realizada em 11 unidades federativas: Alagoas, Paraíba, Rio Grande do Norte, Pernambuco, Goiás, Mato Grosso, Mato Grosso do Sul, Rondônia, Minas Gerais, São Paulo e Paraná, qualificando trabalhadores oriundos do setor Sucroalcooleiro, sejam trabalhadores desempregados que buscam retornar a cadeia produtiva da cana de açúcar, ou empregados que perderão seus postos de trabalho, devido à mecanização da colheita que, por conseguinte necessitarão de qualificação para permanecer no setor.

Os PlanSeQs devem obrigatoriamente estar articulado com outras políticas públicas de emprego.

A meta de Minas Gerais no PlanSeQ 2008, era a qualificação de 545 (quinhentos e quarenta e cinco) trabalhadores no setor de produção de açúcar e álcool e trabalhadores sem ocupação, com um saldo positivo, obteve 
-se ao final do projeto 531 (quinhentos e trinta e um) trabalhadores treinados nos seguintes cursos: eletricista de manutenção industrial, mecânico de manutenção industrial, soldador, caldeireiro industrial, operador de colheitadeira de cana e mecânico de manutenção de máquinas agrícolas, atividades demandas pelas indústrias.

Cabe esclarecer que para o pleno atendimento da pretendida meta, necessariamente deve-se enfatizar a realidade local na qual as estratégias do PlanSeQ serão aplicadas, bem como a estipulação de uma progressiva prioridade da destinação das vagas no curso de qualificação ás comunidades, pois é inegável que dentre os municípios que serão atendidos pelos cursos de qualificação,existem várias realidades regionais.

O estudado da demanda de qualificação em termos das ocupações segundo o Código Brasileiro de Ocupação (CBO) e a necessidade de inserção de trabalhadores (as) no mercado de trabalho, com base nestas premissas foi sugerida a qualificação dos trabalhadores, em atividades e ou profissões, que se dará mediante a aplicação de cursos, que serão aproveitados para a agricultura e pelas indústrias.

A qualificação proposta pelo PlanSeQ Sucroalcooleiro Nacional atenderá a 12.600 trabalhadores em onze unidades federativas: Alagoas (1.005 educandos), Goiás (1.774 educandos), Mato Grosso (1.022 educandos), Mato Grosso do Sul (897 educandos) Minas Gerais (1.390 educandos), Paraíba (527 educandos), Pernambuco (1.794 educandos), Rio Grande do Norte (100 educandos), Rondônia (200 educandos), e São Paulo (2.833 educandos), atingindo diversas cidades no interior dos Estados.

Em atividades e/ou profissões assim distribuídas:

1. A serem aproveitadas na agricultura: eletricista de trator e de colhedora, instrutor de plantação de mudas, motorista canavieiro, operador de colhedora automotriz de cana, mecânico de trator e de colhedora.

2. A serem aproveitadas na indústria: torneiro mecânico, soldador, caldeireiro, mecânico e instalações industriais 


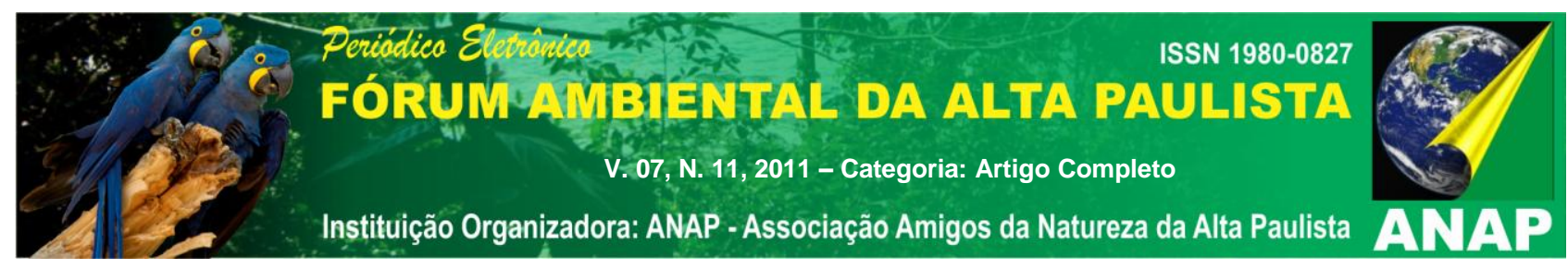

(manutenção), eletricista de instalações comerciais e residenciais, eletricista de instalações de veículos automotores, operador de empilhadeira, auxiliar de manutenção e mecânico de automóveis em geral.

O orçamento para o projeto é de $R \$ 10.987 .200,00$ (dez milhões novecentos e oitenta e sete mil e duzentos reais), conforme cálculo feito a partir do custo aluno/hora $(R \$ 4,36)$ máximo estabelecido pelo FAT ( Fundo de Amparo ao Trabalhador) e a meta de quaficandos. $O$ total do montante do recurso será formado por $95 \%$ recursos do MTE , FAT e $5 \%$ pelas entidades conveniadas, conforme Tabela 3

Tabela 3: Matriz de Financiamento por Unidade Federativa

\begin{tabular}{|c|c|c|c|c|}
\hline $\begin{array}{c}\text { ESTADO } \\
\text { FEDERATIVO }\end{array}$ & $\begin{array}{c}\text { META } \\
\text { EDUCANDOS }\end{array}$ & $\begin{array}{l}\text { VALOR DO } \\
\text { CONVÊNIO }\end{array}$ & $\begin{array}{c}\text { VALOR DA } \\
\text { CONTRAPARTIDA }\end{array}$ & $\begin{array}{c}\text { VALOR DO } \\
\text { REPASSE } \\
\text { DO } \\
\text { MINISTÉRIO }\end{array}$ \\
\hline Alagoas & 1005 & 876.360 & 43.818 & 832.542 \\
\hline Goiás & 1774 & 1.546 .928 & 77.346 & 1.469 .582 \\
\hline Mato Grosso & 1022 & 891.184 & 44.559 & 846.625 \\
\hline Mato Grosso do Sul & 897 & 782.184 & 39.109 & 743.075 \\
\hline Minas Gerais & 1390 & 1.212 .080 & 60.604 & 1.151 .476 \\
\hline Paraíba & 527 & 459.544 & 22.977 & 436.567 \\
\hline Paraná & 1058 & 922.576 & 46.129 & 876.447 \\
\hline Pernambuco & 1794 & 1.564 .368 & 78.218 & 1.486 .150 \\
\hline Rio Grande do Norte & 100 & 87.200 & 4.360 & 82.840 \\
\hline Rondônia & 200 & 174.400 & 8.720 & 165.680 \\
\hline São Paulo & 2833 & 2.470 .376 & 123.519 & 2.346 .857 \\
\hline TOTAL & 12600 & $R \$ 10.987 .200,00$ & $\mathrm{R} \$ 549.359$ & $R \$ 10.437 .841$ \\
\hline
\end{tabular}

Os estados com maior quantidade de qualificandos encontramse nos Estados de São Paulo, Pernambuco e Goiás e proporcionalmente receberão recursos maiores para viabilizar as metas estipuladas pelo PlanSeQ.

\section{CONCLUSÃO}

O fim das queimadas traz um ganho muito relevante para a sociedade na questão ambiental, não só para a saúde das populações que 


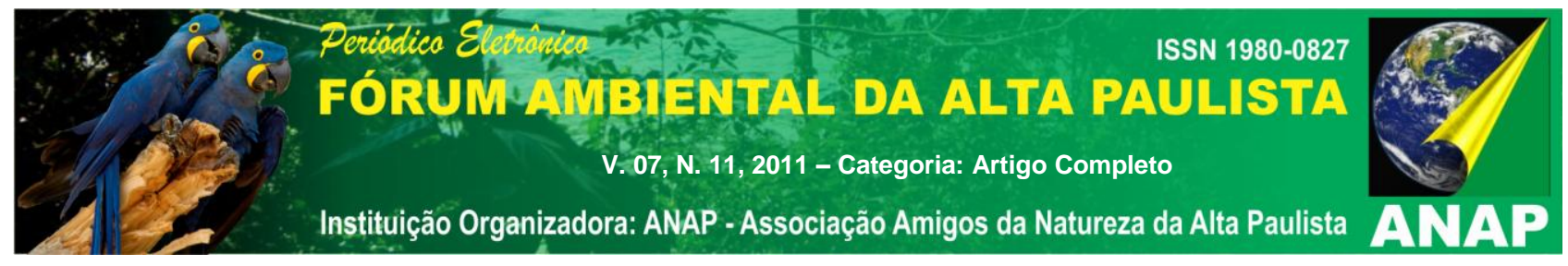

vivem em regiões canavieiras, mas também em nível mundial por estar deixando de emitir $\mathrm{CO}_{2}$.

Contudo é necessária uma articulação entre agentes públicos, privados e do terceiro setor no sentido de elaborar propostas de qualificação conectadas com um desenvolvimento local, inclusive na região de origem dos trabalhadores rurais, viabilizando e apoiando a qualificação também proposta por usinas, municípios e terceiro setor.

A qualificação proposta para os trabalhadores rurais deve ser baseada em políticas públicas que busquem efetivamente contribuir para a melhoraria das condições de vida e falta de oportunidade econômica, inserindo-os no contexto do desenvolvimento regional.

A iniciativa governamental de qualificação através do PlanSeQ Plano Setorial de Qualificação é muito interessante porém se comparada à necessidade do setor ainda representa pouco pela necessidade da mecanização.

O setor sucroalcooleiro contribui efetivamente com cerca de $2 \%$ do PIB nacional, e necessariamente deve ser envolvido com mais responsabilidade social, visto que esta também é uma condição exigida pela comunidade internacional para a plena inserção do etanol como combustível renovável em substituição ao combustível fóssil.

\section{REFERÊNCIAS}

Agencia FAPESP Noticias. Cana sem queima, disponível em:

http://agencia.fapesp.br/13817?sms ss=email\&at $x t=4 d c 45715 a 34 d o c 42 \% 2 C O$. Acessado em 26/7/2011.

ALVES, F. Porque morrem os cortadores de cana? Saúde e Sociedade, São Paulo, v.15, n. 3, p. 90-98, São Paulo, 2006. ISSN 0104-1290

ALVES, F. Políticas Públicas compensatórias para mecanização do corte - indo direto ao ponto. Revista Ruris, v 3, n 1, 2009. ISSN 1980-1998. 


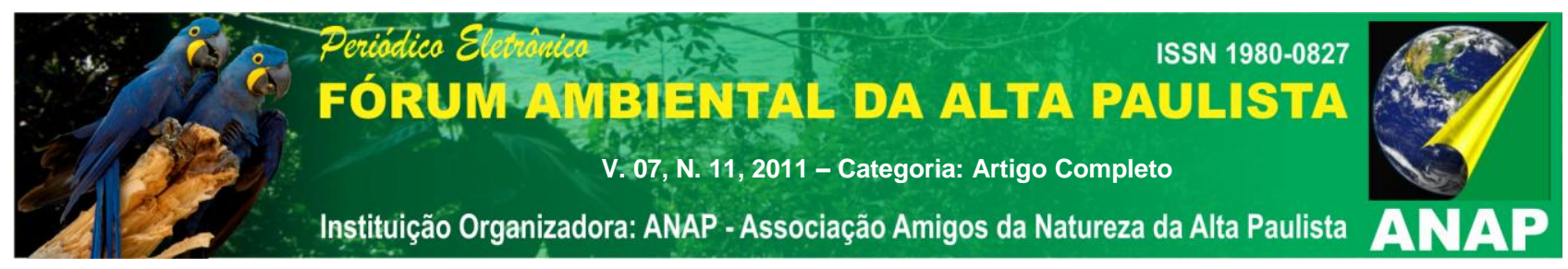

ALESSI N. P.; NAVARRO, V.L. Saúde e Trabalho rural: o caso dos trabalhadores da cultura canavieira na região de Ribeirão Preto, São Paulo, Brasil, Caderno de saúde pública, v.13, suppl2, Rio de Janeiro. 1997.ISSN 0102-311X

ANSELMI. R. Restrição à queima alavanca mercado de colhedoras In Jornal da Cana, julho, n. 163, p-70, Ribeirão Preto-SP 2007.

BACARIN.J.G,GEBARA.J.J,BORGES J.C. Avanço da mecanização canavieira e alterações na composição, na ocupação, na sazonalidade e na produtividade do trabalho em empresas sucroalcooleiras, no Estado de São Paulo. Informações Econômicas, SP, v.40, n.9, set.. 2010. ISSN 0100-4409

BACCARIN. J.G, BORGES, J. C. Jr. Boletim Ocupação Formação Sucroalcooleira em São Paulo, N. 20 Jaboticabal SP. 2011.

BACCARIN. J.G, BORGES, J. C. Jr Boletim Ocupação Formação Sucroalcooleira em São Paulo, N. 21 Jaboticabal SP .2011.

BUZOLIN,P.R.S. (1997) Efeitos do palhiço residual da colheita mecanizada, associada a fontes de potássio de doses de nitrogênio no solo e nas socas de cana açúcar. 98p. Dissertação (Mestrado) - Universidade Estadual" Julio de Mesquita Filho", Jaboticabal SP.1997.

CARDOSO, T de F. OLIVEIRA J.T.A. BRAUNBERK. O.A. Capacitação da mão de obra no setor sucroalcooleiro paulista necessidades e motivações, Informações Econômicas, SP, v. 40 , n. 10 , out . 2010. ISSN 0100-4409

Companhia Nacional de Abastecimento, Acompanhamento da Safra Brasileira - Cana de Açúcar- Safra 2011/12, Primeiro Levantamento Maio 2011. Publicação trimestral. Brasília. 2011. Disponível em: www.conab.gov.br Acessado em 27/07/2011.

EDITAL O PLANSEQ SUCROALCOOLEIRO NACIONAL, Edital de Chamada Pública de Parceria SPPE/TEM n. 24/2010 Ministério do Trabalho e Emprego Secretaria de Políticas Públicas de emprego SPPE, Departamento de Qualificação DEQ. Brasília 2010. Disponível em: http://portal.mte.gov.br. Acessado em 30/07/2011

MORAES, D.F.A.M. O mercado de trabalho da agroindústria canavieira: desafios e oportunidades. Economia. Aplicada. Vol. 11 no. 4 Ribeirão Preto OctlDec.. 2007. ISSN 14138050

NERY, M. S Desempenho operacional e econômico de uma colhedora em cana crua. 2000.108p. Dissertação (Mestrado) - Escola Superior de Agricultura "Luiz de Queiroz" , Universidade de São Paulo, Piracicaba-SP. 2000. 


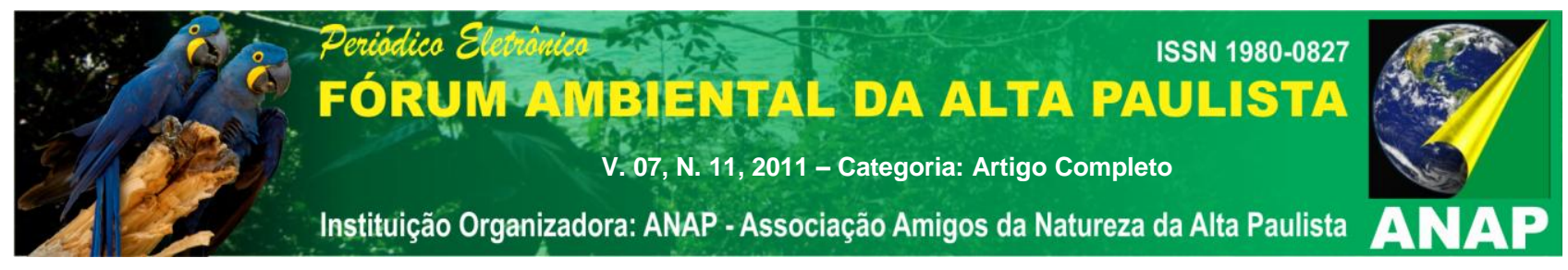

RIBEIRO, H.; FICARELLI, T. R. A Queimadas nos canaviais e perspectivas dos cortadores de cana de açúcar em Macatuba, São Paulo. Saúde e Sociedade, v.19n. 1 São Paulo Jan/Mar.2010. ISSN0104-1290

SILVA, M. A. M. Trabalho e trabalhadores da região do "Mar da cana e do Rio do Álcool". Revista Agrária, São Paulo n. 2, p.2-39. 2005. ISSN 1808-1150

VIEIRA,G; PINHEIRO.F.A. Os possíveis efeitos econômicos e sociais, em consequência da eliminação gradativa da queima da palha e do corte mecanizado da cana-de-açucar. In Energia Agricultura, Botucatu, vol.19, n.3, p.63-71.. 2004 